\title{
Documenting Local History: A Case Study in Digital Storytelling
}

Suzanna Conrad

\section{Introduction}

Telling personal stories with the use of multimedia can be a powerful way to create narratives. Personal stories can function as a means of building community by connecting community members to one another through a shared archived history. In an age where the exchanging of personal letters is no longer the standard (Cox, 2008) digital storytelling is a new form for documenting an individual's experiences, whether through multimedia video creations, blogs, podcasts, activities on social networks, or other story forms.

The practice of digital storytelling can effectively achieve a number of purposes including outreach and activism, education, and the archiving of local history. For the purposes of this article the function of digital storytelling for archiving local history is investigated through the author's journalled experiences as an intern for a digital storytelling project at Monterey Park Bruggemeyer Library, a public library in Southern California. Within the scope of thi grant-funded project twenty-four community members were selected to tell a personal or community story, which was recorded, edited, and published on the Web by library staff and volunteers. The main goal of the project was to archive stories from community members thereby documenting pieces of local history.

Over the course of this project, the library achieved a secondary goal of educating the community about digital storytelling practices and technology. Best practice guidelines for community digital storytelling projects were determined and refined. These guidelines were later used in future digital storytelling projects and included the clear determination of project goals; resources and guidelines for setting up the project; planning distribution and promotion of finished stories; and establishment of clear administrative functions for project management.

\section{Digital Storytelling Defined}

The term digital storytelling was first used by Dana Atchley, one of the founders of the Center for Digital Storytelling in Berkeley, California, in the 1980s (Rossiter, 2010). Atchley made frequent use of multimedia digital tools during storyteller performances to develop stories consisting of moving images, music, and pictures (McLellan, 2006). According to Lambert (2010) digital stories can reference all different types of moments in a storyteller's life whether they are about people, events or places. Rossiter (2010: 37) defines digital storytelling as "vignettes" in which stories are developed out of digital multimedia. Howell and Howell (2003) 


\section{Documenting Local History: A Case Study in Digital Storytelling}

Suzanna Conrad

reference a simple definition of a digital story as a story created in digital format using different types of digital media. Poletti (2011: 73) refers to the "practice" of digital storytelling, or the "production of life narrative through intensive workshops," the result of which is a digital story.

Digital stories can be valuable for documenting history as they provide a "legacy of cultural heritage" (Joseph, 2006: n.p.). According to McLellan (2006: 70), digital storytelling "helps people tell stories from their own lives that are meaningful to them and to their audience, using media to add power and resonance, and to create a permanent record." Digital stories can document culture through history offering a representation of who someone is at a certain point in time (Czarnecki, 2009). Hartley (2009) characterizes digital storytelling as a form of democraticized journalism in which those participating contribute to expanding knowledge.

Additionally, through the use of digital multimedia, storytelling can modify the way that stories are told thereby deviating from traditional storytelling practice (Crane, 2008). In this sense digital storytelling is an enhancement of the traditional storytelling process (Czarnecki, 2009). Digital stories can illustrate not just personal history but also local history, and in the process utilize new types of media and methods of storytelling that differ from those traditionally utilized. The idea of digital storytelling using different methods to tell a story is by no means a new idea; Crawford (2003) for instance discusses how the use of multimedia in videos creates a different method of storytelling than the traditional methods used in books and fiction.

Due to an ever-growing interest in digital media and in user-generated content a number of institutions have established or published best practice for creating digital stories. The Center for Digital Storytelling defines seven steps for digital storytelling (Lambert, 2010) that are intended to assist the storyteller during the inception, development, and publication of a digital story. Bernajean Porter of DigiTales, a digital storytelling initiative, references six elements of a good story or principles to keep in mind when telling a story that encourage emotional involvement and interest from the viewer (Davidson and Porter, 2005).

While these two sources establish good theoretical practice through steps and guidelines, the actual hands-on production process of digital storytelling requires more technical and project management related competencies. Chung (2007) lists a number of project necessities required to make a digital storytelling process successful such as a script, a storyboard, and the necessary technical tools for production of the story. This last necessity requires use of editing software such as Window's MovieMaker, iMovie, Adobe Elements, etc. Czarnecki (2009) mentions a number of different software programs, which may be useful for digital storytelling including online storyboarding tools; editing tools such as Windows MovieMaker, iMovie, Final Cut Pro, Pinnacle Studio, VideoStudio Pro, online web application such as Animoto and VoiceThread; music and sound software such as FindSounds, 


\section{Documenting Local History: A Case Study in Digital Storytelling}

Suzanna Conrad

GarageBand, Audacity and iTunes; and photo editing software such as Photoshop, iPhoto, GIMP, Picnik, Pixlr and Splashup. Once decisions are made regarding what software and hardware to utilize, training must occur for those involved in the project. Decisions on compression formats must also be made to determine what the best format would be to share and distribute to the target audience.

Inherently a project that documents history or a personal experience using a digital story as the means would require preservation to be available in years to come. Creating a digitized story that is posted on the Internet may enable greater access to previously inaccessible resources, however according to McCargar (2007) just digitizing alone is a form of "benign neglect," not a solution for preserving that item long-term. Technological obsolescence, according to the Digital Preservation Coalition's handbook on managing digital materials (Jones and Beagrie, 2001), represents the most imminent threat to preserving digital materials long-term since technology can change in two to five years. Current practices in managing digital files for long-term preservation include combinations of bitstream copying; refreshing to new mediums; creating persistent, physical copies of digital assets; preserving the technology along with the digital asset; migrating to new technology; among others (ICPR, 2007-2012). How preservation of digital stories will be managed is an important consideration in any project, especially as managing preservation of digital assets can be a time consuming and daunting task.

During the production of a digital story a storyteller must be aware of copyright restrictions on any inserted music or photos, especially if $\mathrm{s} /$ he is using digital media that s/he has not authored himself (Czarnecki, 2009). Creative Commons sites such as ccMixter and Freesound provide access to Creative Commons music content available for both commercial and non-commercial use. Similarly, the Library of Congress, Print and Photographs Online Catalog, Flickr, Wikimedia Commons, and NARA among others offer Creative Commons licensed content and public domain content that may be available for commercial and non-commercial purposes. It is important to develop an understanding of copyright restrictions as well as perform due diligence on the specific content items to determine whether or not the content should or could be integrated in a digital story.

When making digital stories freely available on the Internet, the rights of the individuals sharing their stories should not be forgotten. Oral history projects have historically faced both legal and ethical challenges (DeBlasio et al, 2009) because the concept of consent refers to not only the consent to participate in the research, but also the consent to share or assign the copyright of a story for the purpose purported by the interviewer. Shopes (2010) outlines general best practice for obtaining consent from oral history participants, which are just as relevant for interviews with digital storytellers including making the "purpose, scope, and value of the interview" clear to the interviewee (pp. 138). Similarly, Shopes discusses the importance of completing release forms so that the usage of the interviews is allowed for purposes of research, study, publication, etc. In most cases a legal 


\section{Documenting Local History: A Case Study in Digital Storytelling}

Suzanna Conrad

release form would transfer the copyright to the interviewer or organization conducting the interviews (2010).

\section{Th Purposes of Digital Storytelling}

In current literature on digital storytelling a number of purposes and goals become apparent. One purpose for digital stories is for outreach and activism with a clear intention of influencing and swaying public opinion. Secondly, digital storytelling can be implemented for educational purposes at all levels of learning both to teach students about the nature and practice of developing stories as well as to introduce them to new technology. Lastly, digital storytelling can function as a way of archiving history, especially local history, and thereby create a new way to generate micro-histories.

Digital storytelling can allow individuals to represent the world around them using what Couldry (2008: 41) defines as a "shared infrastructure," which can invigorate the community thereby encouraging participation, action, or perhaps just emotion. According to Erstad and Wertsch (2009) through the sharing of this one person's experiences the community can become more involved, and a dialog can be created. When the individual, by sharing their own story, creates this spirit of mediation and interaction, the community can participate and further develop or re-use stories. This idea of community engagement and involvement is also referenced by Thumim (2009) with the concept that storytellers see storytelling as a way to represent themselves, often even politically, or to debunk certain common beliefs about specific topics as shown in Vivienne's (2011) investigation of gender identity using digital storytelling. The storyteller can thereby share their ideals and convictions with the greater public and possibly sway the viewer's perspective and opinion.

Using digital storytelling for educational purposes is one that is frequently visited in both scholarly literature and industry publications both as a means to develop storytelling skills and to learn new technologies (Rebmann, 2012; Coleborne and Bliss, 2011; Subramaniam, 2012). Crane (2008) discusses classroom experiences with students developing digital movies or online storybooks and how these tasks helped students to improve communication skills. Digital stories can also assist students in developing critical assessment skills so that they can adequately critique media that they are presented with on a day-to-day basis (Howell and Howell, 2003).

E-learning is quickly becoming a standard part of curricula around the world as a result of the prevalence of computer-assisted teaching and learning management systems. Digital storytelling, according to Drotner (2009), can enable media literacy in a new way. Due to the necessity of competency in the usage of technology students can gain these practical technological skills during a digital storytelling 


\section{Documenting Local History: A Case Study in Digital Storytelling}

Suzanna Conrad

project. Digital storytelling is therefore "well-positioned" to help teachers use technology effectively in their classrooms especially with the incorporation of usergenerated content in curricula (Robin, 2008: 222). Shuyan and Hong (2010 similarly stress the importance of integration of technology into the curriculum and the possibilities for additional student engagement, critical thinking skills development, and project-based learning. In Yang and Wu's (2012) study of ESL high school students similar learning strategies are gleaned with many of the involved students showing improved communication and critical thinking skills.

A last purpose of digital storytelling, and one that is to be further investigated within this case study, is the function of archiving history an creating micro-histories using digital storytelling. Hartley (2009: 206) envisions digital storytelling as a piece of a "cultural process," one that fosters not only history but also local community. Individuals coming together as a group to create and document public history through digital storytelling have been explored in literature and practice (Coleborne and Bliss, 2011; Czarnecki, 2009). Even though these micro-histories might not be relevant or applicable in the larger community, autobiography can, according to Kaare and Lundby (2009), function as a new way to collect documentation about specific individual experiences and perspectives.

\section{Th Digital Storytelling Project Scope}

The digital storytelling project referenced in this case study was completed as part of a grant project at Monterey Park Bruggemeyer Library, a city library located in Southern California. Twenty-four stories from local community members were selected, recorded, edited, and published on the Web for the purpose of documenting the history of the local community. In order to understand the processes of this project the author's experiences as the intern on the project were journalled, documents distributed in training sessions were analyzed, and an interview was conducted with the librarian in charge of the project to better understand the motivations behind collecting the stories and how the library intended to assess the overall success of the project.

It is important to note that the content generated in this digital storytelling project consisted solely of video-based stories. The stories were recorded on iMac webcams or camcorders, imported to an iMac for editing in iMovie, compressed to specific QuickTime formats, and distributed via a video-sharing website. There are many additional forms of media, which could be considered as a type of digital story, including but not limited to blogs, audio narratives and social networking activities, however, these types of media are not addressed within this case study. The digita stories created within the scope of this project were three to ten minute stories with video recordings of storytellers narrating, which were interspersed with video inlays, photographs, music, and audio effects. 


\section{Documenting Local History: A Case Study in Digital Storytelling}

Suzanna Conrad

The grant application documentation stated that the greater purpose of the project was to assist libraries with preserving memories of their own communities. The librarian in charge of the project asserted that her understanding of the purpose was to make local history more accessible to the community. To achieve this purpose the library worked together with the local arts and culture commission, the local museum as well as other organizations in attempts to promote the project throughout the city. The librarian stressed the importance of making film available and accessible to everyone (Costales, 2011). Because the digital stories in this project were solely video-based, it was possible to achieve the purpose of making film and filmmaking practice accessible to the broader community.

\section{Digital Storytelling in Practice}

As part of the grant the library received the basic equipment necessary for creating digital stories including an iMac, a handheld video camera, an external hard drive for backing up stories and data, a scanner, audio mixer and microphones, light kits, a small portable backdrop, and other accessories required to make this a plug and play station. The institution administering the grant program invited staff at the library and volunteers interested in participating in the project to a one-day training event on site. During this visit, the trainers delivered the equipment and spent a full day introducing the elements of digital storytelling to the staff and volunteers. This was a three-part seminar in which the elements of the video creation process were detailed: the development of a story, the recording process, and the editing process. The institution administering the grant program also preloaded the iMac with guides and documentation reinforcing the detailed processes taught during the training sessions.

At the start of the project there were approximately four volunteers, two library technicians, and one intern trained in editing stories in iMovie. Two librarians and an intern were trained in the storytelling process, which included establishing the story line and recording the individual. As the project progressed this distribution of work changed. One of the editing volunteers was well versed in filmmaking as an independent filmmaker himself, and he filmed ten of the twenty-four stories. An intern and a library clerk were assigned part-time to work on the project; both filmed and edited stories. The library technicians were only involved in an auxiliary capacity and would step in if the library clerk, intern, or volunteers were not available. The librarians were involved in a supervisory capacity in the filming and editing process, and otherwise focused on selecting storytellers, scheduling them, collecting release forms from storytellers, and promoting the project in the community. There were two to three volunteers from the original training day who 


\section{Documenting Local History: A Case Study in Digital Storytelling}

Suzanna Conrad

were not available to help on the project. One volunteer film student was recruited during the project to assist with a particularly challenging on location digital story. The distribution of paid versus volunteer work was imperative in ensuring the project's success.

One theme from the literature on digital storytelling that emerged in practice was the complexity of establishing a compelling story. Since the digital stories in this project were not recorded or edited by the storytellers themselves, rather the storytellers were encouraged by librarians to share some local experience, at times the storytellers required guidance to find a compelling story. The storytellers had varied levels of comfort with cameras and public speaking. Some required scripting of their story, which they would read from a strategically placed computer screen. Others required notes, which they held or which were displayed on a computer screen. Some storytellers who were accustomed to public speaking were able to tell a story without requiring any coaching or scripting. The challenge of working with these experienced storytellers presented itself when attempting to limit the story length, i.e. a fluid storyteller often had difficulty limiting their story to less than ten minutes. The preferred time for a story was five minutes or less.

After filming the digital stories, the footage would be distributed to the editors, who handled editing the stories, overlaying images where relevant, inserting audio where appropriate, compressing the videos for release on the web, and uploading the digital stories onto a video-sharing site for public viewing. Promotion did not stop with the upload to this video-sharing site, rather it was a multi-step process. The digital stories were embedded on the library website (http://www.ci.montereypark.ca.us/index.aspx?page=2021) on a digital storytelling page linked from a local history page describing the storytelling project and other local history projects. Pursuant to the suggestions from the organization administering the grant, the library also scheduled a screening event in which seven stories were selected for public viewing. All storytellers were presented with copies of their stories on DVD.

\section{Challenges}

The institution providing grant support effectively supplied the library with the tools and training to create digital stories, however, there were still a number of challenges faced during the process including issues dealing with the greater community, technical issues, and operational issues. All such issues were logged in a journal and best practice was established to deal with these issues by initiating shared communication. Internal knowledge transfer was achieved through the creation of manuals, support documentation, and further training of individuals joining the project at later dates. Specific instances of these attempts to facilitate communication will be detailed in the following paragraphs. 


\section{Documenting Local History: A Case Study in Digital Storytelling}

Suzanna Conrad

At the start of the project, the librarians began compiling lists of potential participants, who might have an interesting story worth documenting. Initially there was a great deal of interest in participation, however, without continual follow-up it was challenging to encourage the storytellers to come in for the actual recording. To address these issues the librarians offered multiple appointment times and confirmed appointments one day in advance to be sure that the storytellers would be available and present. Even though the storytellers were informed that the library would require photographs or some other sort of supporting informational media for the editing process, some storytellers were not prepared on the day of filming and had to bring in materials at a later time. This required further follow-up and persistence. Storytellers were also required to sign a release before filming began to confirm that they understood the purposes of the filming and to ensure that the library could use the produced media according to the terms of the project. Throughout the task of recruiting storytellers it became imperative that the librarians make active efforts to keep the project moving as it became easy for the project to stall and not move forward when no storytellers were available for filming (Costales, 2011).

In some cases, the storyteller had a fascinating story to tell, however no photographs to share. For these instances, research on public domain and Creative Commons licensed content was conducted. Where appropriate these images were utilized in stories with corresponding text indicators so that the viewer would not be led to believe that these photos were in fact from the storyteller's personal collection. When such resources were used, a credits screen was inserted at the end of the story referring to the source per public domain or Creative Commons attribution guidelines. This process required a fundamental understanding of copyright restrictions, ability to determine the copyright status of certain materials, and an understanding of Creative Commons licenses.

It became apparent after the first stories were recorded that audio was the most important part of the digital story. Audio guided the user through the story regardless of whether video of the storyteller or images were displayed and for this reason it was very important to have a clean audio recording. At times this was challenging as storytellers became nervous in front of the camera and in some cases fidgeted or made noises with paper scripts or other objects.

The amount of time needed for editing could also be reduced by cleaner filmmaking. For instance, encouraging a filmmaker to reduce the number of clips recorded likewise reduced the time needed to create the final cut. This could be challenging with a nervous storyteller, e.g. encouraging him or her to complete their story in one take was not always possible. This was additionally encouraged by the institution supporting the grant, however, not always adhered to due to previous experience in postproduction amongst the filmmakers and editors. 


\section{Documenting Local History: A Case Study in Digital Storytelling}

Suzanna Conrad

Operational issues were the last, albeit the most significant challenge. Throughout the project, managing volunteer and staff resources was imperative to avoid duplication of work and maximize time usage. After a few instances of duplicated work, a spreadsheet was created where volunteers and staff would log time using the digital storytelling equipment. This spreadsheet logged the date, stories worked on, what was completed on that day, what still had to be completed, and if the file was ready for upload. Videos were only uploaded to a video-sharing site by the intern after approval from the librarian to ensure a final review process before the content was available on the Internet. Creation of this spreadsheet log and review process helped to avoid confusion amongst the different staff members and volunteers working on the project.

Knowledge transfer to the library's employed staff was imperative for the long-term continuation of the project since many of the resources on this project were temporary. The first way in which this was completed was through the creation of manuals documenting all the steps in the storytelling process including the recording process, the editing process, and the process of finalizing videos and content. Documents included screenshots, walkthroughs, and relevant login information where applicable. All documents were compiled into one manual and distributed amongst library employees who would be using the digital storytelling equipment in the future. In addition, an external version was created without the logins and sensitive data so that external parties could also reference the manual without having access to the library's websites and video-sharing site accounts.

At the end of the project the library forwarded the high-resolution videos on data DVDs to the organization administering the grant so that the videos could be imported to a server there for preservation. Additionally, the library maintained copies on an external hard drive and backups to data DVDs. While it might be more desirable to have a preservation management plan at the local library, many community organizations face similar challenges when attempting to archive locally (Cannon, 2009). With this joint approach of managing backups locally and having the archival masters saved on a central server, Monterey Park Bruggemeyer Library attempted to address initial issues with long-term preservation.

\section{Discussion}

While much has been presented regarding the practical implications of this specific project, the fundamental goals of the project as they pertain to the literature review should be addressed. Pieces of personal local history were recorded through the documentation of twenty-four stories of local interest. Three clear themes from the local community emerged throughout the project: multiculturalism, art, and local history. The full collection of digital stories is available at the following link: 


\section{Documenting Local History: A Case Study in Digital Storytelling}

Suzanna Conrad

http://www.ci.monterey-park.ca.us/index.aspx?page=2021 and on blip.tv at http://blip.tv/monterey-park-stories.

One example of a story that developed from a simple highlight of a local organization to a greater partnership between the library and that organization occurred with the filming of a short digital story about the Chinese American Citizens Alliance. The Vice-President of Planning for this organization was contacted to participate in the digital storytelling project. In his two-minute video he described the mission of the Chinese American Citizens Alliance and some of the opportunities the organization provides for youth programs including scholarship programs, volunteer programs for a youth council, and other programs that supported Chinese American high school students during their college admission processes (Wu, 2011). While his specific video highlighted the experiences and projects that these hig school students had previously participated in as part of the organization, the awareness that he developed of additional available library resources fostered a continued partnership between the library and the Chinese American Citizens Alliance. Specifically, after his story was recorded the storyteller began to ask about the equipment and people that were working on the digital storytelling project to inquire if it might be possible to create a similar project for his high school students. Once the digital storytelling project had concluded, the library embarked on a new partnership with this prior storyteller in which high school students interviewed previous mayors of Monterey Park, California for an oral history collection. The hig school students were able to use the equipment and recording rooms within the library to record their interviews. This development of an educational opportunity for local high school students was a surprising and encouraging example of how community involvement and education about digital storytelling was fostered in a digital storytelling project that had previously been intended to simply document local history. The initial storyteller, impressed by the digital storytelling processes and technology available at the library, involved further members of the community in creating and documenting local history.

Since the project had been promoted in partnership with the local arts and cultural commission from the inception, it was easy to find artists and writers to participate. Most of the artists and writers spoke about their inspiration in creating a specific piece or installation, or how they began their careers or hobbies initially. Many of these stories invoked emotional remembrances of the storytellers' pasts or childhoods. In one story, a playwright described her interest and passion in writing a story about the controversies from the 1980's in Monterey Park, California regarding the official language of the community. The "English Only" movement, as discussed and detailed in Horton (1995), was a conflict that the storyteller witnessed first hand as a teenager growing up in Monterey Park. In her digital story, she shared her experience writing a play about the controversy and conflict. Her story detailed her fascination with the topic that eventually resulted in a play geared toward representing and involving the community. She made a statement that the play was not only about what the language of the community should be, but "how 


\section{Documenting Local History: A Case Study in Digital Storytelling}

Suzanna Conrad

did we come together as a community and communicate even beyond the language" (Lee, 2011). This story served the purpose of documenting her experience, but also represents how the community in some ways has grown and progressed, while also drawing attention to the fact that the community still has growing to do. Her digital story, and her play, functioned as a means of documenting public history through an autobiographical experience much like the "cultural process" described by Hartley (2009).

A third exemplary story was a personal story from the curator of the Monterey Park Historical Museum, which detailed her experiences growing up as the daughter of a well known doctor in the community. The storyteller originally had been asked to give us a tour of the Monterey Park Historical Museum. After she described the museum and its history, two digital stories about her childhood were filmed one of which was specifically about her family and her father. Because of her father's role and involvement in the community, she had a number of historic images from her childhood of interesting locations in the local community including the site of their house across from a community landmark (the Monterey Park Cascades Waterfall), her father's office on a main street in Monterey Park, the local park and amphitheater, the Mount Lowe Railway, and the historic local hospital, which has since been rebuilt in a different location. She described her experiences as the curator of the museum and how this involvement has also creating some story sharing experiences with other local community members, many of whom share their memories of her father. During her story, she often smiled at details of her father's antics and experiences, poking fun at her parents' initial hesitation to take yearly vacations. She became emotional when talking about her father's death, however expressed appreciation that he gave her "the community of Monterey Park" (Walker, 2011). Through this personal and emotional ten-minute story, the storyteller created and documented local history through autobiography.

The experiences of the three storytellers described above are examples of the ways in which storytellers became more involved in the library and community, or digitally documented their own experiences thereby contributing to the local historical record. There was, however, also a digital storytelling "community" that developed amongst library staff as a result of this project. Shortly after the grant project concluded, staff members began to use the equipment to present other library programs including online storytime and book recommendation videos. Many staff members contributed their time to read a children's book to the video camera or presented and summarized a new book from the collection. While these developments did not continue to build the local historical record, they did engage the library staff with digital storytelling techniques and technologies.

Due to the sheer number of volunteers involved in the project, local community members were engaged in the digital storytelling process in a number of different capacities. Volunteers participated in filming and editing the stories, the storytellers themselves were all volunteers, and many of the community members willingly 


\section{Documenting Local History: A Case Study in Digital Storytelling}

Suzanna Conrad

attended receptions and events presenting a selection of digital stories. This project directly initiated the mayors' oral history recordings with the Chinese American Citizens Alliance and the library online storytelling project. Further volunteers were engaged including the high schoolers, who filmed and edited the oral histories, and local community members such as the chief of police who participated in online storytime by reading children's books on camera. These volunteers learned more about the storytelling process and when involved in the hands-on activities of filming and editing, they also learned about the techniques utilized for digital storytelling. The library acted as a community space for this facilitation.

\section{Conclusion}

In the case of Monterey Park Bruggemeyer Library stories from the local community were effectively recorded and distributed, allowing anyone with Internet access to experience these stories of local historical significance. The stories were preserve locally and at a central location on a server to ensure long-term access to the digital stories. Local community members also benefitted from the new services available at the library either through access to stories created on an ongoing basis by the library or through the supervised usage of the digital storytelling equipment for purposes beyond the prior scope of library programming. At Monterey Park Bruggemeyer Library digital storytelling effectively fostered community outreach and involvement and contributed to the building of a local historical record in digital form. 


\section{Documenting Local History: A Case Study in Digital Storytelling}

Suzanna Conrad

\section{References}

Cannon, B. (2009), Preserving communities: a guide to archiving for community organizations, B. Cannon: Halifax, N.S.

Chung, S. (2007), “Art education technology: digital storytelling”, Art Education, Vol. 60 No. 2, pp. 17-22.

Coleborne, C. \& Bliss, E. (2011), “Emotions, digital tools and public histories: digital storytelling using Windows Movie Maker in the history tertiary classroom", History Compass, Vol. 9 No. 9, pp. 675-685.

Costales, C. (2011) Untitled. Interviewed by [blinded for review] [in person] Monterey Park Bruggemeyer Library, March 29, 2011.

Couldry, N. (2009), "Digital storytelling, media research and democracy: conceptual choices and alternative futures", K. Lundby (Ed.), Digital storytelling, mediatized stories: Self-representations in new media, P.Lang, New York, NY, pp. 41-60.

Cox, R.J. (2008), Personal archives and a new archival calling, Litwin Books, LLC, Duluth, MN.

Crane, B. (2008), "Digital storytelling changes the way we write stories", Information Searcher, Vol. 18 No. 1, pp. 1, 3-9, 35.

Crawford, W. (2003), “The Crawford files”, American Libraries, Vol. 34 No. 10, pp. 59.

Czarnecki, K. (2009), Digital storytelling in practice, ALA TechSource, Chicago, IL.

Davidson, H. \& Porter, B. (2005), "The art of digital storytelling”, available at:

http://digitales.us/resources/bjps-books-articles (accessed September 12, 2011).

DeBlasio, D.M., Ganzart, C.F., Mould, D.H., Pashen, S.H., and Sacks, H.L. (2009).

Catching stories: a practical guide to oral history, Swallow Press, Athens.

Drotner. K. (2009), "Boundaries and bridges: Digital storytelling in education studies and media studies", K. Lundby (Ed.), Digital storytelling, mediatized stories: Self-representations in new media, P.Lang, New York, pp. 61-84.

Erstad, O. and Wertsch, J.V. (2009), "Tales of mediation: Narrative and digital media as cultural tools", K. Lundby (Ed.), Digital storytelling, mediatized stories: Selfrepresentations in new media, P.Lang, New York, pp. 21-40. 


\section{Documenting Local History: A Case Study in Digital Storytelling}

Suzanna Conrad

Hartley, J. (2009), "Problems of expertise and scalability in self-made media”, K. Lundby (Ed.), Digital storytelling, mediatized stories: Self-representations in new media, P.Lang, New York, pp. 197-211.

Horton, J. (1995), The politics of diversity: immigration, resistance, and change in Monterey Park, California, Temple University Press, Philadelphia, PA.

Howell, D., \& Howell, D. (2003). "What's your digital story?", Library Media Connection, Vol. 22 No. 2, pp. 40.

Interuniversity Consortium for Political and Social Research (ICPSR). "Digital preservation management: implementing short-term strategies for long-term problems", available at http://www.dpworkshop.org/index.html (accessed 1 June 2013).

Jones, M. and Beagrie, N. (2001) Preservation management of digital materials: a handbook. The British Library, London, available at http://www.dpconline.org/component/docman/doc_download/299-digitalpreservation-handbook (accessed 11 June 2013).

Joseph, L. C. (2006), “Digital storytelling”, MultiMedia \& Internet@Schools, Vol. 13 No. 4, pp. 13-16.

Kaare, B.H. and Lundby, K. (2009), "Mediatized lives: Autobiography and assumed authenticity in digital storytelling", K. Lundby (Ed.), Digital storytelling, mediatized stories: Self-representations in new media, P.Lang, New York, pp. 123-144.

Lambert, J. (2009), Digital storytelling: capturing lives, creating community ( $3^{\text {rd }}$ ed.), Digital Diner Press, Berkeley, CA.

Lee, A. (2011), "English only", available at: http://blip.tv/monterey-parkstories/english-only-4998500 (accessed 26 April 2013).

McCargar, V. (2007), "Kiss your assets goodbye: best practices and digital archivin in the publishing industry", Seybold Report: Analyzing Publishing Technologies, Vol. 7 No. 16, pp. 5-7.

McLellan, H. (2006), "Digital storytelling in higher education", Journal of Computing in Higher Education, Vol. 19 No. 1, pp. 65-79.

Poletti, A. (2011), "Coaxing an intimate public: life narrative in digital storytelling", Continuum: Journal of Media \& Cultural Studies, Vol. 25 No. 1, pp. 73-83.

Rebmann, K. (2012), "Theory, practice, tools: catching up with digital storytelling", Teacher Librarian, Vol. 39 No. 3, pp. 30-34. 


\section{Documenting Local History: A Case Study in Digital Storytelling}

Suzanna Conrad

Robin, B. R. (2008), “Digital storytelling: A powerful technology tool for the 21st century classroom”, Theory into Practice, Vol. 47 No. 3, pp. 220-228.

Rossiter, M., \& Garcia, P. A. (2010), "Digital storytelling: A new player on the narrative field", New Directions for Adult and Continuing Education, Vol. 2010 No. 126, pp. 37-48.

Shopes, L. (2008), "Legal and ethical issues in oral history", Charlton, T.L., Myers, L.E. and Sharpless, R. (Eds.), Handbook of oral history, Altamira Press, Lanham, MD, pp 135-169.

Shuyan, W., \& Hong, Z. (2010), "Enhancing teaching and learning with digital storytelling", International Journal of Information \& Communication Technology Education, Vol. 6 No. 2, pp. 76-87.

Subramaniam, M. , Ahn, J. , Waugh, A. , \& Druin, A. (2012), "Sci-fi, storytelling, and new media literacy", Knowledge Quest, Vol. 41 No. 1, pp. 22-27.

Thumim, N. (2009), “'It's good for them to know my story': Cultural mediation as tension", K. Lundby (Ed.), Digital storytelling, mediatized stories: Self-representations in new media, P.Lang, New York, pp. 85-104.

Vivienne, S. (2011), "Trans digital storytelling: everyday activism, mutable identity and the problem of visibility", Gay \& Lesbian Issues and Psychology Review, Vol. 7 No. 1, pp. 43-54.

Walker, B. (2011), "Growing up in the Walker family", available at: http://blip.tv/monterey-park-stories/williamsberylweb-5252313 (accessed 26 April 2013).

Wu, W. (2011), "Chinese American Citizens Alliance”, available at: http://blip.tv/monterey-park-stories/chinese-american-citizens-alliance-4998382 (accessed 26 April 2013).

Yang, Y. \& Wu, W. (2012), “Digital storytelling for enhancing student academic achievement, critical thinking and learning motivation: a year-long experimental study", Computers \& Education, Vol. 59, pp. 339-352. 